\title{
Osteossíntese de úmero por xenoenxerto ósseo preservado em mel em pombos domésticos (Columba livia $)^{1}$
}

\author{
Humerus osteosynthesis for xenograft bone preservated in honey \\ in pigeons (Columbia livia)
}

\section{Leandro Haczkiewicz Gaiga ${ }^{2}$ João Eduardo Wallau Schossler ${ }^{3}$}

\section{RESUMO}

Este experimento teve por objetivo avaliar clínica histológica e radiograficamente o emprego de fibula e tíbia canina, preservadas em mel, no tratamento de fratura transversa diafisária de úmero em pombos domésticos (Columba livia). Foram estudados 14 pombos. A indução e a manutenção da anestesia foi feita com halotano e a fratura foi realizada na diáfise do úmero direito com serra oscilatória, e, logo após, estabilizada por xenoenxerto ósseo inserido dentro do canal medular e associado a fio de aço interfragmentar. $O$ tempo médio e o desvio padrão para restabelecimento do vôo foi de 24,81 \pm 3,65 dias. $O$ tempo médio e o desvio padrão para a consolidação óssea foram de $41 \pm$ 4,74 dias. Uma ave não apresentou consolidação óssea. Ocorreu reabsorção do xenoenxerto aos 180 dias. A técnica proposta é eficiente para o tratamento de fratura de úmero em pombos domésticos (Columba livia). Os resultados obtidos nesse experimento demonstram que o mel é adequado como meio de preservação de xenoenxerto ósseo cortical.

Palavras-chave: asa, aves, fratura

\section{ABSTRACT}

In this study an osteosynthesis technique of diaphyseal transverse humeral fractures with preserved canine fibula or tibia in honey was evaluated in pigeons by clinical, histologic and radiographic observations. Fourteen pigeons were studied. Anesthesia was induced and mainteined with halothane. A transverse right midshalft humeral fracture was created using an oscillating bone saw. The fracture was reduced, and the xenograft was inserted intramedullary early and associated with cerclage wire. The mean + standart deviation for bone healing were $41 \pm 4.74$ days. The mean \pm standart deviation for flight capability were $24.81 \pm 3.65$ days. The bone resorption of the xenograft occured in 180 days. The proposed surgical technique is apropriated for humeral fractures in domestic pigeons (Columba livia) and the results of this study showed that honey is appropriate preservation of xenografts.

Key words: wing, birds, fracture.

\section{INTRODUÇÃO}

A osteossíntese do úmero das aves constitui um desafio para o cirurgião veterinário, devido principalmente as suas características anatômicas e à necessidade de perfeita redução da fratura para que seja mantido o uso funcional da asa (YAMAZOE et al., 1994). O úmero das aves é um osso pneumático com uma grande cavidade medular, córtex fino e com alto conteúdo de cálcio, o que o torna quebradiço e favorece a ocorrência de fratura iatrogênica (WEST et al., 1996).

Deve-se dar especial atenção a manutenção do alinhamento rotacional durante a correção de fraturas de úmero em aves, pois um leve desalinhamento resulta em perda da função de aerofólio da asa e significativa alteração no vôo (LEVITT, 1989; BENNET \& KUZMA, 1992). WILLIAMS et al. (1987) observaram que alterações no comprimento do úmero não afetaram a capacidade de uso funcional da asa, ao contrário de mau alinhamento, deformidades angulares e rotacionais.

\footnotetext{
'Parte da Dissertação de Mestrado em Medicina Veterinária apresentada pelo primeiro autor à Universidade Federal de Santa Maria (UFSM).

${ }^{2}$ Médico Veterinário, Mestre, Professor Substituto da Universidade Federal do Rio Grande do Sul, Faculdade de Veterinária, Av. Bento Gonçalves, 9090, 91540-000, Bairro Agronomia, Porto Alegre-RS. E-mail: gaiga@bol.com.br Autor para correspondência.

${ }^{3}$ Médico Veterinário, Professor Adjunto, Departamento de Clínicas de Pequenos Animais, UFSM.
} 
É contra-indicado o uso de imobilização externa em fraturas de úmero de aves, pois essa promove rapidamente a atrofia muscular e anquilose da articulação que podem levar à não união óssea por desuso do membro (BENNET \& KUZMA, 1992). KUZMA (1995) recomenta que a fisioterapia deve ser iniciada logo após a reparação da fratura e BUSH (1977) relata ainda que o uso do membro fraturado durante a reparação da fratura diminui o tempo de consolidação da mesma.

WEST et al. (1996), ao realizarem estudo da cicatrização óssea de úmero de pombos, relataram a formação de extenso calo cartilaginoso após um período de duas semanas de fratura. WILLIAMS et al. (1987), ao tratarem fratura de úmero e ALIEVI (2000), ao tratar fratura de tibiotarso em pombos, verificaram que, devido a esse calo cartilaginoso, os sinais clínicos de consolidação óssea acontecem antes que os sinais radiográficos.

Uma variedade de métodos tem sido relatada para a osteossíntese de úmero em aves (WILLIAMS et al., 1987; YAMAZOE et al., 1994), porém são adaptações de procedimentos utilizados em mamíferos, as quais, devido ao peso excessivo do implante, necessitam de uma segunda intervenção para sua remoção após a consolidação óssea, o que aumenta a taxa de morbidade desses animais (WANDER et al., 2000).

Enxertos ósseos corticais são biodegradáveis e têm sido usados no tratamento de fraturas em aves, porém com resultados controversos. MACCOY \& HASCHEK (1988) realizaram osteossíntese de úmero em pombos com alo e xenoenxertos esterilizados com óxido de etileno e mantidos à temperatura ambiente. Os enxertos foram associados com uma alta incidência de deiscência da incisão, formação de seqüestro ósseo e reação a corpo estranho, indicando alto índice de rejeição tanto ao aloenxerto quanto ao xenoenxerto pelo receptor. Já WANDER et al. (2000), utilizando pinos confeccionados de xenoenxertos ósseos corticais estocados a $-70^{\circ} \mathrm{C}$, não observaram sinais de rejeição ao xenoenxerto e sim, de incorporação do enxerto ao calo ósseo. Porém, apesar do uso de imobilização externa, em $20 \%$ dos animais, ocorreram fraturas do xenoenxerto na primeira semana de pós-operatório.

Existem vários meios e métodos de preservação de ossos corticais que visam diminuir a antigenicidade do enxerto, além de manter um estoque de ossos disponível (STEVENSON, 1998). O mel tem sido utilizado na preservação de aloenxertos ósseos com sucesso, além de ser uma substância de fácil aquisição, manipulação, estocagem e baixo custo.
AMENDOLA (2001) reparou defeito ósseo em cães utilizando aloenxerto conservado em mel. Concluiu que o mesmo foi adequado como conservante de ossos para serem utilizados como implantes corticais, pois manteve o material livre de agentes patogênicos e não houve sinais compatíveis com rejeição nos animais de seu experimento. A rigidez óssea manteve-se em um grau adequado durante o transcorrer do estudo e ocorreu incorporação do enxerto ao leito receptor.

JENKINS (1992) recomendou que os mesmos cuidados com a dor, preconizados em mamíferos, sejam utilizados em aves e indica como analgésico e antiinflamatório o flunixin meglumine na dose de 1 a $10 \mathrm{mg} / \mathrm{kg}$, a cada $24 \mathrm{hs}$ ou de acordo com as circunstâncias.

Perante esses fatos, o presente trabalho teve como objetivos avaliar clínica, histológica e radiograficamente o uso de segmento de fíbula ou tíbia canina preservados em mel, associado a fio de aço interfragmentar, no tratamento de fratura transversa diafisária de úmero em pombos domésticos (Columba livia), e ainda, avaliar a viabilidade do mel como meio de preservação de xenoenxerto ósseo cortical canino.

\section{MATERIAL E MÉTODOS}

As fíbulas e tíbias foram obtidas de cães livres de doenças infecto-contagiosas. Após secção nas epífises, foi feita remoção do periósteo e restos musculares, lavagem com água corrente e acondicionamento em frascos contendo mel. Os enxertos foram armazenados à temperatura ambiente por um período entre 30 dias e seis meses antes da utilização.

Foram estudados 14 pombos, machos e fêmeas, adultos, com peso entre 280 e 380 gramas, mantidos em gaiolas individuais de $1 \mathrm{~m}^{3}$, nas quais permaneceram por um período mínimo de 15 dias antes do procedimento cirúrgico para adaptação às pessoas responsáveis pelo seu manejo, ao local e à alimentação ${ }^{a}$.

Três horas antes da cirurgia, foi instituído jejum alimentar; a indução e manutenção da anestesia foi feita com halotano $0^{\mathrm{b}}$. Após o animal estar em plano anestésico cirúrgico, foi realizada a remoção manual das penas localizadas na face medial da região do úmero direito e, em seguida, anti-sepsia do local com solução de gluconato de clorexidina $4 \%$. Como terapia antimicrobiana profilática, foi aplicada, por via intramuscular, enrofloxacina ${ }^{\mathrm{d}}$ na dose de $10 \mathrm{mg} \mathrm{kg}^{-1}$.

Após abordagem da diáfise ventral, foi feita osteotomia da porção diafisária média do úmero direito, utilizando-se uma serra oscilatória, criando-se uma fratura transversa. Após a osteotomia, foram feitos 
quatro orifícios paralelos à linha de fratura com uma broca de $0,8 \mathrm{~mm}$, dois no fragmento ósseo proximal e dois no fragmento ósseo distal, pelos quais foram inseridos dois fios de aço $\mathrm{n}^{\underline{0}} 0^{\mathrm{e}}$, um fio para cada fragmento ósseo. O segmento de fíbula ou tíbia canina foi moldado para ocupar cerca de $80 \%$ do diâmetro da cavidade medular e medir $2 / 3$ do comprimento da diáfise do úmero. Foi utilizada a técnica de "Shuttle"(BENNETT \& KUZMA, 1992) para inserção do segmento no canal medular. Primeiramente, o segmento ósseo canino foi perfurado no seu centro com uma broca de $0,8 \mathrm{~mm}$ e por esse orifício foi passado um fio de mononáilon $\mathrm{n}-2-0^{\mathrm{f}}$. Em ato contínuo, o segmento foi introduzido por via retrógrada, na porção intramedular proximal do úmero (Figura 1A) entre o fio de aço e o endósteo. Após a redução da fratura, o segmento foi tracionado pelo fio de mononáilon para a porção distal do úmero, até coincidir o orifício do segmento com a linha de fratura, sendo então removido o fio de mononáilon. Posteriormente foi feito o nó das extremidades dos fios de aço configurando uma hemicerclagem em oito (Figura 1B). Na seqüência foi realizada redução do espaço morto com vycril $n^{\circ} 5-0^{\mathrm{g}}$, em sutura contínua simples, e rafia de pele com o mesmo fio.

No pós-operatório, foi realizada administração de flunixin meglumine ${ }^{\mathrm{h}}$ na dose única de $5 \mathrm{mg} / \mathrm{kg}$ por via intramuscular, inspeção visual diária para verificar-se o estado geral da ave e recuperação da função do membro envolvido e exame clínico semanal da ferida cirúrgica.

Ao ser constatada a formação de calo palpável clinicamente, os animais foram transferidos para um viveiro $(8,30 \mathrm{~m}$ de comprimento $\mathrm{x} 4 \mathrm{~m}$ de largura $\mathrm{x} 3,10 \mathrm{~m}$ de altura) para encorajar o uso do membro. As aves foram avaliadas semanalmente quanto à recuperação do vôo, sendo este considerado restabelecido quando as mesmas conseguiram voar oito metros na horizontal e três metros na vertical.

Os exames radiográficos da asa direita foram realizados em todas as aves, em incidências ânteroposterior e latero-lateral, imediatamente após o término da cirurgia e em intervalos de tempo conforme indicado na tabela 1. Na avaliação radiográfica, foram observados o alinhamento da fratura e o tempo necessário para consolidação óssea e perda de radiopacidade do xenoenxerto.

Após 15, 30, 45, 60, 90 e 180 dias do procedimento cirúrgico, foi realizada eutanásia de duas aves em cada período, utilizando uma dose total de $75 \mathrm{mg}$ de tiopental sódico pela via intracelomática, para avaliação macroscópica e microscópica da região enxertada. Na avaliação macroscópica, foi observada
Tabela 1 - Exames radiográficos pós-operatórios dos pombos domésticos (Columbia livia) submetidos a osteossíntese por xenoenxerto ósseo preservado em mel.

\begin{tabular}{lcccccccccc}
\hline $\begin{array}{l}\text { Número } \\
\text { da ave }\end{array}$ & \multicolumn{1}{c}{ Avaliação radiográfica (dias de pós-operatório) } \\
\hline P1 & 15 & 22 & 29 & 36 & 45 & 60 & 90 & 120 & 150 & 180 \\
P2 & 15 & 22 & 29 & 36 & 45 & 60 & 90 & 120 & 150 & 180 \\
P3 & 15 & 22 & 29 & 36 & 45 & 60 & 90 & 120 & 150 & 180 \\
P4 & 15 & 22 & 29 & 36 & 45 & 60 & 90 & 120 & 150 & 180 \\
P5 & 15 & 22 & 29 & 36 & 45 & 60 & 90 & - & - & \\
P6 & 15 & 22 & 29 & 36 & 45 & 60 & 90 & - & - & \\
P7 & 15 & 22 & 29 & 36 & 45 & 60 & - & - & - & - \\
P8 & 15 & 22 & 29 & 36 & 45 & 60 & - & - & - & - \\
P9 & 15 & 22 & 29 & 36 & 45 & - & - & - & - & - \\
P10 & 15 & 22 & 29 & 36 & 45 & - & - & - & - & - \\
P11 & 15 & 22 & 29 & - & - & - & - & - & - & - \\
P12 & 15 & 22 & 29 & - & - & - & - & - & - & - \\
P13 & 15 & & - & - & - & - & - & - & - & - \\
P14 & 15 & & - & - & - & - & - & - & - & - \\
\hline
\end{tabular}

a presença ou não de mobilidade óssea na linha de fratura e comparação do úmero tratado com seu contralateral para verificação da presença ou ausência de deformidade rotacional, angular e alteração do comprimento, sendo esta avaliada com auxílio de um paquímetro. Após registro fotográfico, foram desprezadas as epífises do úmero direito para que fosse fixado em formol tamponado a $10 \%$. Passado um período mínimo de 72 horas, foi descalcificado em solução de ácido nítrico a 10\%. Após a descalcificação, o úmero direito foi processado pela técnica histológica de inclusão em parafina e coloração por hematoxilinaeosina, para avaliação microscópica do arranjo celular.

\section{RESULTADOS E DISCUSSÃO}

Em dois animais $(14,28 \%)$, ocorreram fraturas oblíquas no momento da osteotomia com a serra oscilatória devido, principalmente à cortical muito fina e quebradiça, que pode levar à ocorrência de fraturas iatrogênicas, como observado por WEST et al. (1996). O tipo de fratura, entretanto, não influiu na formação de calo ósseo, no tempo para consolidação óssea e no uso do membro.

A técnica de osteossíntese utilizada conseguiu aposição dos fragmentos e alinhamento da fratura em todas as aves (Figura 2A). Uma delas apresentou deformidade rotacional, o que levou ao mau funcionamento do membro, concordando com o observado por LEVITT (1989) e BENNET \& KUZMA (1992), ao afirmarem que um leve grau de rotação resulta em significativa alteração na habilidade de voar e 


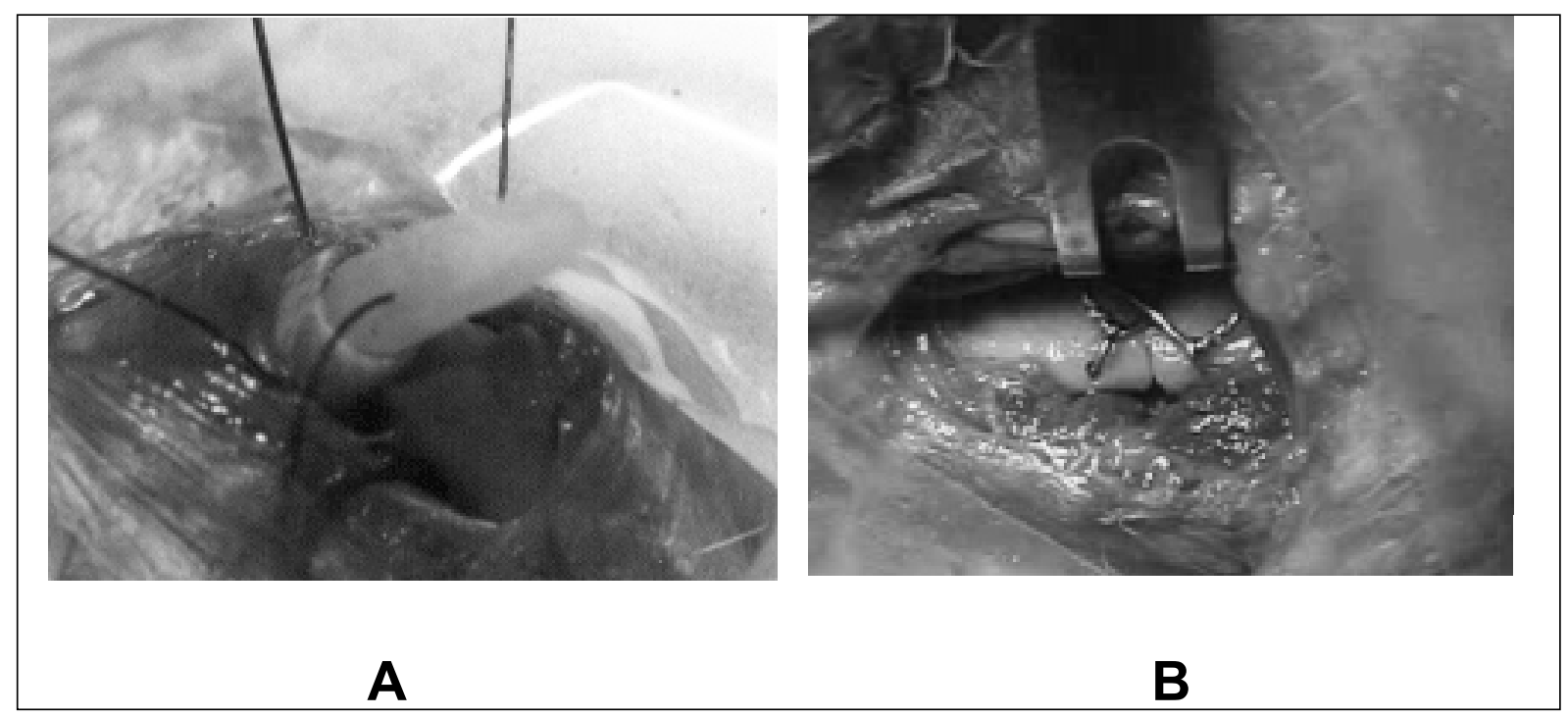

Figura 1 - Osteossíntese de úmero por xenoenxerto ósseo em pombo doméstico (Columbia livia).A - Inserção do segmento de xenoenxerto por via retrógrada na porção intramedular proximal do úmero, entre o fio de aço e o endósteo, juntamente com o fio de mononáilon. B - Redução da fratura e fechamento dos nós das extremidades dos fios de aço, configurando uma hemicerclagem em oito.

conseqüentemente ao não uso do membro e à não união óssea. $\mathrm{O}$ fato de as aves apresentarem redução no comprimento do úmero que variou de 0,5 a $1 \mathrm{~mm}$ não afetou o uso do membro e a capacidade de voar. WILLIAMS et al. (1987) relataram que alterações de 2 a $6 \mathrm{~mm}$ de comprimento no úmero de pombos não interferiram no retorno da função do membro, desde que não houvesse a presença de deformidades angulares e rotacionais.

Aos 15 dias de pós operatório, o exame radiográfico não demonstrava a presença de calo ósseo formado ou ausência de linha de fratura, mas, ao exame clínico, observava-se a presença de calo externo palpável, além de todos os animais apresentarem uso funcional do membro operado. Ao exame histológico realizado nessa data, observou-se a formação de um calo constituído por cartilagem hialina, como encontrado por WEST et al. (1996). Esse calo proporcionou união e estabilização dos fragmentos, mas manteve a linha de fratura radiograficamente visível, concordando com o relatado por WILLIAMS et al. (1987) e ALIEVI (2000), de que, os sinais radiográficos de consolidação óssea acontecem mais tardiamente que os sinais clínicos.

O tempo médio e o desvio padrão para o restabelecimento do vôo das aves foi de 24,81 $\pm 3,65$ dias. A não utilização de bandagem imobilizatória e a transferência dos animais para um viveiro, ao se constatar a presença de calo externo palpável, foi feita com o objetivo de encorajar o uso do membro operado e proporcionar um retorno precoce à função, como é recomendado por KUZMA (1995). BUSH (1977) relata que o uso do membro fraturado, durante a reparação da fratura, diminui o tempo necessário para a consolidação óssea, concordando com o observado no presente estudo, no qual o tempo de formação de calo ósseo e consolidação da fratura teve correlação significativa com o restabelecimento do vôo.

O tempo médio e o desvio padrão para consolidação óssea pelo estudo radiográfico foi de 41 \pm 4,74 dias, sendo semelhante ao observado por WILLIAMS et al. (1987), utilizando fixador esquelético externo, e YAMAZOE et al. (1994) utilizando placas de aço associadas a acrílico autopolimerizável, dois métodos de osteossíntese que promovem rígida fixação. Ao exame histológico realizado aos 45 dias, observavou-se calo ósseo constituído por trabéculas de osso trançado em fase de reabsorção.

Assim como relatado por AMENDOLA (2001), o xenoenxerto do presente estudo apresentou um aspecto físico bastante viável, não se observando fissuras longitudinais ou rachaduras ao ser retirado do mel. A rigidez óssea foi mantida, como se pode observar durante a moldagem do segmento com a lima ou serra oscilatória. Mesmo sem a utilização de bandagem imobilizatória, não ocorreu fratura de nenhum enxerto após a sua implantação no úmero das aves, diferente do observado por WANDER et al. (2000) que obtiveram uma taxa de fratura do xenoenxerto de $20 \%$ no pós-operatório. 
Apesar de o método de coleta utilizado ter sido realizado através de condições não assépticas, não ocorreram sinais clínicos de infecção associados aos enxertos no presente estudo. Esse fato corrobora com o resultado de AMENDOLA (2001), ao preservar aloenxertos ósseos corticais em mel, o que comprova que o enxerto ósseo preservado nessa substância não necessita de coleta asséptica.

Ao exame radiográfico realizado aos 180 dias de pós-operatório, de quatro animais avaliados, todos xenoenxertos $(100 \%)$ apresentaram aspecto radiolucente (Figura 2B) e ao exame histológico os mesmos apresentavam-se completamente reabsorvidos. Diferente do observado por MACCOY \& HASCHEK (1988), não houve sinais de rejeição ao xenoenxerto do presente experimento, estando esse incorporado ao osso receptor a partir dos 90 dias de pós-operatório (Figura 3), resultado semelhante ao encontrado por WANDER et al. (2000) e AMENDOLA (2001), o que demonstra a capacidade do mel em reduzir a antigenicidade do xenoenxerto ósseo cortical.

A utilização do flunixin meglumine em dose única e exame da ferida cirúrgica a cada sete dias visaram diminuir o contato físico com as aves, pois sabe-se que essas são animais sujeitos a estresse, e quanto maior a manipulação, maior é a chance de desencadeamento desse processo. A dose de flunixin meglumine utilizada neste experimento ficou de acordo com a recomenda por JENKINS (1992). Não ocorreram quaisquer complicações associadas ao uso do produto e, apesar de ser utilizado em dose única, nenhum animal apresentou no pós-operatório os sinais clínicos de dor, como inatividade e anorexia.

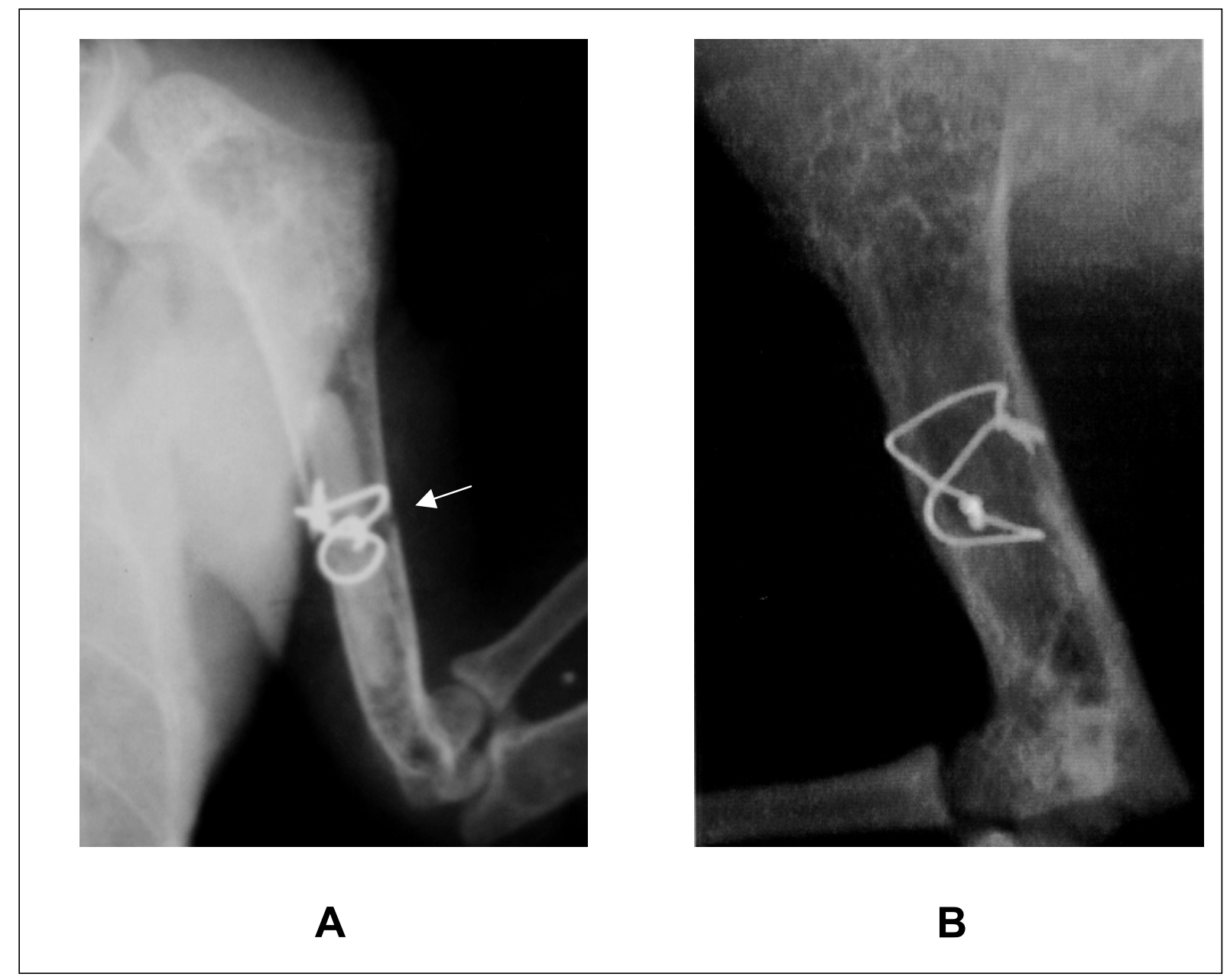

Figura 2 - Osteossíntese de úmero por xenoenxerto ósseo em pombo doméstico (Columbia livia).Imagem radiográfica no pós-operatório imediato (A). Observa-se a presença da linha de fratura (seta), aposição e alinhamento dos fragmentos ósseos. Imagem radiográfica aos 180 dias de pós-operatório (B). Observa-se o aspecto radiolucente do xenoenxerto. 


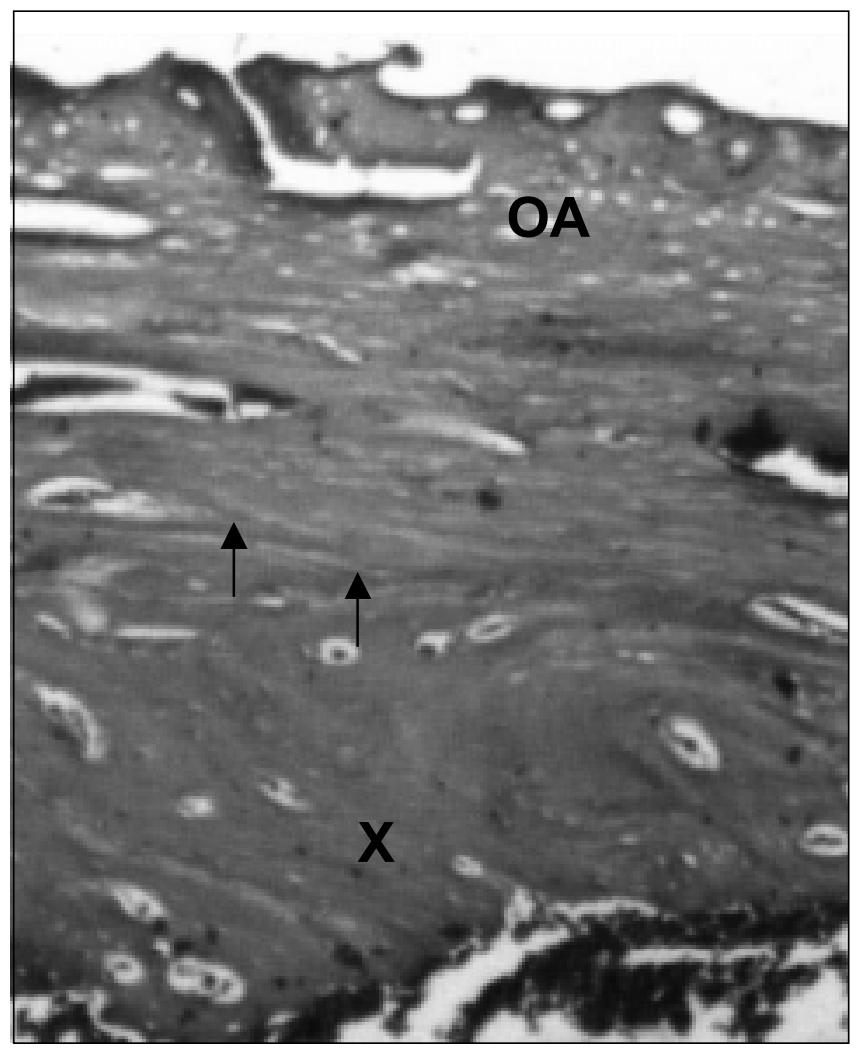

Figura 3 - Osteossíntese de úmero por xenoenxerto ósseo em pombo doméstico (Columbia livia).Aspecto histológico de amostra óssea 90 dias após a fratura. Observa-se continuidade óssea (setas) entre o xenoenxerto (X) e o osso da ave (OA).

\section{CONCLUSÕES}

A técnica de osteossíntese proposta é eficiente para o tratamento de fratura diafisária transversa do úmero de pombos domésticos (Columba livia), dispensando um segundo procedimento cirúrgico para a remoção do implante.

Perante as condições do presente experimento, o mel demonstra ser adequado como meio de preservação de xenoenxerto ósseo cortical canino.

\section{FONTES DE AQUISIÇÃO}

a - Ração para aves ornamentais: Anhanbi agroindustrial Ltda. Itapejara, PR.

b - Halotano: Hoerchst do Brasil. Química e farmacêutica S.A. Suzano, SP.

c - Gluconato de Clorexidina 4\%: Vico Farma. Santa Maria, RS.

d - Flotril 2,5\%: Schering-Plough Veterinária. Jacarepaguá, RJ.

e - Aciflex: Ethicon Indústria \& Comércio. São José dos Campos, SP. f - Mononáilon: Ethicon Indústria \& Comércio. São José dos Campos, SP.

g - Vycril: Ethicon Indústria \& Comércio. São José dos Campos, SP.

h - Banamine: Schering-Plough Veterinária. Jacarepaguá, RJ.

\section{REFERÊNCIAS BIBLIOGRÁFICAS}

ALIEVI, M.M. Redução fechada e fixação esquelética externa tipo I ou II para o tratamento de fratura de tibiotarso em pombos domésticos. (Columba livia). 2000. 38f. Dissertação (Mestrado em cirurgia) - Programa de Pós-graduação em Medicina Veterinária, Universidade Federal de Santa Maria.

AMEndola, G.F. Correção de defeito ósseo femural em cães utilizando implante ósseo cortical homólogo conservado em mel. 2001. 46f. Dissertação (Mestrado em cirurgia) - Programa de Pósgraduação em Medicina Veterinária, Universidade Federal de Santa Maria.

BENNETT, R.A.; KUZMA, A.B. Fracture management in birds. Journal of Zoo and Wildlife Medicine, v.23, p.5-38, 1992.

BUSH, M. External fixation of avian fractures. Journal of the American Animal Hospital Association, v.171, p.943-946, 1977.

JENKINS, J.R. Avian soft tissue surgery; Part I. In: ACVS VETERINARY SYMPOSIUM, 1992, Miami, Florida. Proceedings... Miami : The American College of Veterinary Surgeons, 1992. p.631-633.

KUZMA A.B. Avian orthopedics: fracture management I. In: ACVS VETERINARY SYMPOSIUM, 1995, Miami, Florida. Proceedings... Miami: The American College of Veterinary Surgeons, 1995. p.249-251.

LEVITT, L. Avian orthopedics. Compendium on Continuing Education for Practicing Veterinarian, v.11, n.8, p.899-929, 1989.

MACCOY, D.M.; HASCHEK, M.W. Healing of transverse humeral fractures in pigeons treated com ethylene oxidesterilized, dry-stored, onlay cortical xenografts and allografts. American Journal Veterinary Research, v.49, p.106-110, 1988 .

STEVENSON, S. Enxertos ósseos. In: SLATTER D. Manual de cirurgia de pequenos animais. 2.ed. São Paulo : Manole,1998. V.2. Cap.127, p.2006- 2017.

WANDER, K.M. et al. Fracture healing after stabilization with intramedullary xenograft cortical bone pis: a study in pigeons. Veterinary Surgery, v.29, p.237-244, 2000 .

WEST, P.G. et al. Histomorphometric and angiographic analysis of bone healing in the humerus of pigeons. American Journal Veterinary Research, v.57, p.0101015, 1996. 
WILLIAMS, R. et al. A comparative study of treatment methods for long bone fractures. Companion Animal Practice, v. 1, n.4, p.4855, 1987
YAMAZOE, K. et al. The reduction of humeral fracture in pigeons with intramedullary poly ( methyl methacrylate ) and neutralization plate fixation. Journal of Veterinary Medical Science, v.56, p.739-745, 1994. 